\title{
Exam Preparation: Concerns of London Upper Secondary School Students With Implications for Teachers and Teaching
}

\author{
Mark Minott, EdD \\ University of Bristol, Bristol, United Kingdom \\ iD https://orcid.org/0000-0003-0504-489X
}

Contact: minott.mark@icloud.com

\begin{abstract}
The aim of this qualitative case study was to ascertain factors impacting the examination preparation process and causing concerns for London upper secondary students, to learn steps taken to reduce and/or resolve the concerns, and to discuss the implications for teachers and teaching. A subsidiary yet important aim was to give the students a "voice" in the research literature. Using convenient or opportunity sampling, I conducted face-to-face interviews with 14 grade 12 and 13 students, ages 16-18, in a south-west London secondary school. The analysis of the data revealed external factors and a personal need factor, that is the need to pass the exam, impacted the examination preparation process and caused concerns for students. Schools and students have use various solutions to reduce and/or resolve concerns. For example, school-based solutions included offering make-up or additional sessions or extra classes. Students-when faced with large amounts of material and information-employed solutions such as "things-to-do lists" and breaking down tasks into manageable sections. Implications for teachers and teaching include the need for teachers' lesson contents to address factors impacting exam preparation and students' concerns. Teachers also need to equip students to use a variety of revision strategies, encourage students to use social support and ensure that promised extra lessons materialize.
\end{abstract}

Keywords: London; teachers; secondary school; students; external; examination; concerns; personal needs

Date Submitted: January 9, 2020 | Date Published: October 16, 2020

\section{Recommended Citation}

Minott, M. (2020). Exam preparation: Concerns of London upper secondary school students with implications for teachers and teaching. Journal of Educational Research and Practice, 10, 338-350. https://doi.org/10.5590/JERAP.2020.10.1.21

\section{Introduction}

The importance of including students' "voices" or perspectives on issues directly affecting their education and the teaching-learning dynamics to which they are central is now an established feature of the education research literature. See, for example, recent works, such as Bloemert et al., 2019; Walls and Holquist, 2019; Charteris \& Smardon, 2019; Mayes, 2018; and Bourke \& MacDonald, 2018. 
While this is the case, noticeably missing in the literature on many educational issues, including preparation for examinations, is the perspective or "voice" of London secondary students. A search of over 64 databases via the University of Bristol library reflects the missing London students' perspective on issues relevant to this study. I searched the databases using the following terms-secondary students' preparation, examination, London, school and external examination-and found a total of 810 results. None included the perspective of London secondary students on the issues related to this study.

While the "voice' or perspective of London secondary students is missing from the exam preparation literature, the importance of the exam preparation process is reflected in the fact that the topic and tips for engaging the process are well-attended to in the literature. For example, see recent works, such as Ashworth, 2019; Silverman, 2018; The Mix, 2019; and Settlage and Wollscheid, 2019. Further reference and discussion of these and other literature will be made in the literature review section of this paper.

I launched this study based on the trend in the established literature outlined above, the importance of exam preparation to students' success, and my desire as a teacher to aid in the process of including the "voice" or perspective of local secondary school students in the research literature. The qualitative case study aimed to ascertain factors that are impacting the examination preparation process and those causing concerns, that is worried or nervous feelings, for London upper secondary students, to learn steps taken to reduce and/or resolve the concerns, and to discuss the implications for teachers and teaching. By achieving this aim, the study contributes to the literature in several ways. First, it identifies factors impacting examination preparation for local secondary students. Next, the study shares how local school students in London reduce and/or resolve the concerns caused by factors impacting the examination preparation process, thus giving them a "voice" in the research literature.

What follows is a succinct review of the literature on examination preparation, an outline of the research, presentation of the findings, and discussion and implications for teachers and teaching. A summary of key findings is displayed in table form in the Appendix.

\section{Literature Review}

An important aspect of this study was to identify factors impacting examinations and the exam preparation process and those causing concerns for students. In the literature, these can be categorized as examination external factors. External factors are outside the students' control and sometimes result in mental and emotional issues such as exam-related stress. Examples of these factors include an exam-oriented system of education, competitive entrance exams, and parental demands, which result in pressurized exam preparation events. Kirkpatrick and Zhang (2011) spoke about the negative influences of exam-oriented education on Chinese high school students and made the point that it causes extreme stress. This is so because students regard exams as a means to prove their worth. Wang and Yeh (2005), in their study of competitive entrance exams in nursing education, also acknowledged the effects of exam-related stress and highlighted taking an actual test as an important stressor for students. The literature also highlights examination-related anxiety as another factor which impacts students. Deb et al. (2015), in addressing the issues of academic stress, parental pressure, anxiety, and mental health among Indian high school students, made the point that preparing for examinations is a pressurized event and creates a high degree of anxiety in many students. The writers connect the pressures of examination preparation and the resulting student anxiety with the nature of parental involvement and expectations, which are manifested in actions such as parents removing their TV cable connections-presumably to remove it as a distraction, thus forcing students to attend to their studiesand vastly cutting down on their own social lives in order to monitor their children's homework. Myyry and Joutsenvirta (2015), arguing for the use of online testing, believed that students often find traditional testing threatening and that test anxiety is manifested in affective physiological arousal, emotionality, worry, and 
behaviors such as procrastination and avoidance. Locker and Crople (2004), in their study of anxiety, depression, and self-esteem in secondary school children, stated that female students displayed greater levels of anxiety and negative effects immediately before an examination. Participants in this study also experienced mental and emotional issues, such as stress and anxiety resulting from external factors impacting examinations and the exam preparation process.

The literature also provides suggestions regarding how to reduce and/or resolve the concerns caused by external factors impacting the taking of exams and exam preparation. Three of these are highlighted here and can be categorized as either student-based or school- or school system-based. First, schools can deemphasize high-stakes testing (Kirkpatrick \& Zhang, 2011). Arguing the need to deemphasize high-stakes testing to aid in reducing exam stress and anxiety, Kirkpatrick and Zhang pointed out that doing so involves teachers paying more attention to the students' overall development supported by gradual development of an education system not driven by testing. In addition, using rational coping involves problem-focused positive ways of coping (Crego et al., 2016). While the previous solution is school- or school system-based, this one is studentbased, for the individual involved focusses on the problem and finds a positive way to resolve it. The writers gave this example of a rational coping item used in their research, "I tried to analyze the causes of the problem in order to be able to cope with it" (p. 167), and concluded that employing this method of resolving examination-related concerns has a positive impact on student performance and increases their exam-related self-efficacy, which also results in obtaining better grades. Lastly, Weale (2018) wrote that schools help to reduce and/or resolve the concerns caused by external factors impacting exam taking and exam preparation by providing relaxation sessions, yoga classes, extra classes, and resilience programs to support worried pupils.

Speaking specifically of the United Kingdom, Weale (2018) highlighted the external factor of changes and reforms to the GCSE examinations and the concerns this caused secondary students across the UK in regard to taking the examinations and exam preparation. Changes and reforms, said Weale, resulted in stress and serious anxiety among students and this precipitated the introduction of several school-based solutions, such as offering make-up sessions or extra classes, relaxation sessions, yoga classes, and resilience programs to support worried pupils-as mentioned previously. As will be shown later, this external factor also impacted this study participants' exam preparation and caused concerns.

A key external factor is the nature of paper-based examinations, which heavily impacts exam preparation, how this is carried out, and what is included in the process. Independent Thinking (2011) stated that examinations, especially paper based, are a printed set of questions to which the students reply in writing, in silence, and behind closed doors. To be successful, students require the skill or ability to write, recall information, and complete these activities in silence within a given time frame. The development of these skills or abilitiesinfluenced by the nature of examination-pervades literature that focuses on exam preparation. See for example Ashworth (2019), Silverman (2018), and The Mix (2019). This concentration of writings-influenced by the nature of examination-on exam preparation seems to suggest the nature of examinations impacts exam preparation.

While the literature highlights external factors impacting exam preparation and causing concerns for students, there is also the personal need factor, that is the need to pass the exam, which impacts exam preparation. Morgan and King (1975) stated that needs or motives-terms used synonymously-drive us to do the things we do. For example, when asked why they went to college, persons may answer in terms of the need to learn or to gain a good job. Kirkpatrick and Zhang (2011), speaking about the negative influences of examoriented education on Chinese high school students, made the point that the need to pass the exam, "The National Higher Education Entrance Examination," is an objective for all Chinese high school, that is students. This impacts the exam preparation process by making it mainly a ritual of writing and memorizing significant volumes of information. Deb et al. (2015) made the point that students' self-worth in Indian society 
is mostly determined by a good academic performance, which includes the need to "pass the exam" rather than vocational and/or other individual qualities. For the students, the need to "pass the exam" is of great significance because the writers point out that exam failure and academic stress contribute to $6.23 \%$ of Indian students committing suicide every day (Deb et al.). The personal need factor, that is the need to pass the exam, also impacts exam preparation for students in this study.

This succinct review of the literature identified potential factors impacting the preparation for examinations and which caused concerns, that is worried or nervous feelings, for students and what steps were taken to reduce and/or resolve the concerns. However, which factors impact exam preparation and cause concerns for London secondary school students and what steps they took to reduce and/or resolve the concerns were still unknown. Given the centrality of teachers and teaching in the exam preparation process, a subsidiary yet important aspect of the study is a discussion of implications for teachers and teaching.

\section{The Study}

\section{Participants' Selection and Ethical Issues}

Using convenient or opportunity sampling, I interviewed 14 grade 12 and 13 students, ages $16-18$, in a southwest London secondary school face-to-face using an open-ended method. These students were in various classes that I taught; therefore, it was convenient for me to interview them and I took the opportunity to do so. The students were asked if they would participate, and they all agreed. They were also told that their names and that of the school would not be mentioned in the research report. This was adhered to as they were identified by randomly assigned grade levels, for example, Grade 121, 132, 124.

Students in the upper grades were selected because they completed the GCSE and advanced subsidiary (AS) level examinations and were preparing to sit the final A-Levels. For international readers of this paper, the Advanced Level and Advanced Subsidiary General Certificate of Education are qualifications offered by education institutions in the UK. A-levels are studied over 2 years and are recognized as the standard for assessing the suitability of applicants for entrance to academic courses in UK universities (Bhopal, 2015). In addition to their experiences of preparing for examinations, the students were able to consider questions seriously and objectively and clearly express their ideas.

\section{Data Collection and Research Question}

Data were collected over 1 week through individual face-to-face interviews conducted in the school where I worked as a supply or substitute teacher. I chose to interview because I wanted in-depth information. However, another reason for employing this method is that it provides the opportunity to include follow-up, as well as supplementary questions thought of during the actual interview and used as necessary to illuminate or clarify, thus facilitating depth in responses, as suggested by Joffe (2001). Each interview was 5-10 minutes and focused on the student experience of preparing for examinations at GCSE, AS and A-Levels. During each session, I made personal notes of all that was said, and clarification and follow-up questions were sought and asked during the actual interview. I commenced the interview with one open-ended question designed to elicit factors impacting their preparation for examinations and causing concerns. The question was: "Think about your GCSE exams and/or your A-levels exams; as you prepared, what aspect(s) of the process of preparation most concerned you and how did you address this?" Responses were written down almost verbatim. This was made possible via careful listening, the interview venue, which was a side room in the school library, the small number of students and the clarity of the main question. Also, participants were contacted later and asked to check what I wrote and to ensure that it faithfully represented their views (Elliott 1991). Corrections and alterations were made accordingly. 
Minott, 2020

\section{Data Analysis}

Powell and Renner (2003) supported the use of pre-set categories when analyzing data. They also stated that pre-set categories provide direction for what to look for in the data. In light of this, I analyzed the data for the study using the following broad categories taken from the literature-examination external factors and the personal need factor, that is the need to pass the exam. Through a process of careful analysis, which involved reading and rereading and using my judgment and experience, I matched data with the categories. For example, participants referred to the exam factor of memorization using phrases such as "getting all that knowledge in my head" and "not forgetting information." These phrases were placed under the category of personal need factor, that is the need to pass the exam. This was done because the only reason why these thoughts were expressed by and were of concern to participants was the personal need to pass the examination. Participants also referred to the exam factor of managing time using phrases, such as "I was concerned about timing during the practice papers" and "managing social demands." Based on the reason previously given, these were also placed under the category of personal need factor.

Responses also included words and phrases, such as changes to the "GCSE exams," "volume of work to cover," and "pressure to complete timed paper." These and other similar phrases were placed under the category of examination external factors. A similar process was used to categorize the data as school- and student-based solutions used to reduce and/or resolve concerns. In the next section, these categories are used as a template to guide the discussion of findings.

\section{Discussion of Findings}

\section{Examination External Factors}

The study brings to the fore the following examination external factors, which are outside the students' control: teachers not being able to cover all the topics in the syllabus, the bulk or volume of information to learn, changes to the GSCE specifications, teachers underestimating the potential of students-thus not awarding a high predicted grade, competition involved in getting into certain universities, no course work at A levels and completing papers that are timed.

In the next section-which discusses how concerns caused by these factors were reduced and/or resolvedexamples of how these examination external factors impact exam preparation is embedded.

\section{Reducing and/or Resolving the Concerns Caused by Examination External Factors}

Concerns caused by examination external factors were reduced and/or resolved by employing both school and student-based solutions. For example, student participants stated in response to the research question:

The teacher not covering all the topics:

I had to do some topics by myself. The school organized some make-up sessions or extra classes, but those did not happen for a number of reasons. So, I did personal research to get the answers I need. (Student 131)

Even though I am doing 3 subjects at A-levels now the "volume of work" concerns me... I do a "things to do list," break down tasks and practice. If I have an exam or revision for an exam, I write a "things to do list" and this helps. (Student 135)

A close examination of student 131's response revealed that the examination external factor identified, "the teacher not covering all the topics" resulted in the student-during exam preparation-engaging in an additional activity, that is researching topics, which would have been unnecessary had the teacher covered all 
required topics. Also, for student 135, during exam preparation, the volume of information drove her to think about and apply various ways to organize the information. Further examination of these quotations revealed the use of both a student- and school-based solution. The school-based solution of offering make-up sessions or extra classes seemed to be typically employed (Weale, 2018). This, however, is not without its failure-as indicated by student 131. Also, the response of student 131 shows evidence of a student-based solution highlighted by the phrases "I had to do some topics by myself" and "So I did personal research to get the answers I need." This statement suggests that both solution types were, and perhaps are, being employed.

An examination of the response of student 135 also showed she employed a student-based solution to the examination external factor impacting the examination preparation process and causing concern, that is "the volume of work." It is not atypical of the participants in this study to employ student-based solutions. For example, student 135's solution to the volume of work is to employ "things-to-do lists" and break down tasks into manageable sections. Her actions come directly from her being an organized person-her response to a follow-up question regarding why she employed "things-to-do lists." Student 1310, in response to the concerns derived from not being able to complete "timed papers" on time, was forced to sit for mock exams, thus becoming familiar with the pressures associated with this aspect of examinations. In response to the uncertainty of what the exam will contain, student 133 said, "I just studied what the teacher gave me and what I did in class. I soon forgot about content." As a solution to the concern caused by the fact that there is no course work in her chosen A-levels exams that would help if she did not do "well" in an examination, student 139 employed her ability to memorize information and also tried to calm herself. Another example of how examination external factors impact the students' exam preparation can be seen in the response of student 139. The nature of the A-Level, having no course work, seems to force the student to employ extensively the skill of memorization during preparation. More importantly, the actions of the students 1310, 133, and 139 seem to be akin to rational coping-which is a problem-focused positive way of coping (Crego et al., 2016). In other words, solutions employed to reduce and/or resolve the concerns are directly related to the problem (Wang \& Yeh, 2005).

The GCSE changes and reforms in the UK was an examination external factor that impacted exam preparation and caused grave concerns not only for student participants in this study but for many students across the UK (GCSE Changes and Reforms, 2019; Weale, 2018). Both teachers and students had to learn the new requirements and-for teachers-how to implement these. Here are examples of participants' responses in this regard. Also embedded in these are ways that this examination external factor impacts their preparation, such as having to use old or previous examination papers that may not have been relevant and starting the preparation process early.

Changes to the GCSE:

I was not sure about using the old past papers, although I did. I was so worried. I really did a whole lot of past papers. I use mind maps and flash cards. Had I known the different ways of revising that I now know, I would have used them in the GCSEs. I sure use them now. (Student 122)

Changes to the GCSE:

I revised early, started in December of the year before the actual exam. Attend study groups, which were very helpful. I also use different revision methods (Student 124).

For student 122 the unavailability of certain resources, such as past exam papers that were relevant to the new GCSEs, made her "worried." The issue of the availability of relevant resources was raised by Weale (2018), who quoted teachers as saying there were inadequate resources or revision materials. Also, the writer stated that this caused students to become anxious. Weale's study supports the thoughts of student 122.

While Weale (2018) stated that solutions included school-based ones, such as relaxation sessions, yoga classes, and resilience programs to support worried pupils, and extra lessons organized by schools, 
participants in this study employed student-based solutions aided by school resources. For example, student 122 used school-supplied past papers along with mind maps and flash cards. Student 124, however, utilized student-based solutions, such as starting revision the year prior to sitting the actual examinations and attending study group sessions.

The title to this subsection begs the question regarding the success of the solutions employed by study participants to reduce and/or resolve concerns. In response, I will say that it is safe to conclude that the school- and student-based solutions employed reduced and/or resolved the concerns. This is so because they are all in sixth form, which means they have successfully sat a number of GCSEs and the AS or advanced subsidiary level-the first-year exam of A-Levels.

\section{Examination Factors That are a Direct Result of the Personal Need Factor}

The analysis of the data suggests that the following exam factors and associated quotations are not only a direct result of participants' need to pass the exam but indicators of the existence of this need and how it drives thoughts and actions (Morgan \& King, 1975). The examination factors are memorizing information: students spoke of being concerned about "not remembering what I studied" (student 134), "Getting all that knowledge into my head" (Student 136), "Forgetting information" (Student 121) and "Making sure I remember and understand the specifications and keywords in the questions" (Student 123). Managing time: students also spoke of being concerned about exam timing saying, "timing was key: I was concerned about timing during the practice papers. I just remained committed and keep at it" (Student 132). Time management: "I don't leave study to too late" (Student 137). Managing social demands: "concerned with what people say: If you do badly, they may think you are not smart" (Student 1310). Here too, examples of how this personal need factor-the need to pass the exam-impacts exam preparation is embedded in the discussion of how concerns caused by the factor were reduced and/or resolved?

\section{Reducing and/or Resolving the Concerns Caused by the Need to Pass the Exam}

To reduce and/or resolve the concerns caused by this personal need factor, that is the need to pass the exam, both student- and school-based solutions were employed. Student 134 stated in regard to not remembering what was studied-"the school helped by giving frequent assessments, mock exams and papers. These taught me to enjoy the exam and made it fun!" Student 136 stated, "I do a lot of test papers, quizzes and watch and listen to information and stuff related to the topic I am covering." Watching and listening to information and "stuff related to the topic" indicates a student-based solution that would be expected in year 13. It is also safe to conclude that the actions of Student 136 during exam preparation are a direct result of the need to pass the exam.

Other student-based solutions include: "getting someone to ask me questions about the topic I am studying. I do a lot of practice questions and get my teachers to mark them and give me feedback" (Student 121).

"Attending tutorials with my teachers and using mind maps and flash cards" (Student 123). "Going to the teacher or a friend that knows the subject well for information and clarification. Sometimes the students explain it better than the teacher" (Student 138). "I just remained committed and keep at it" (Student 132) and "I don't leave study to too late" (Student 137). Here, it is safe to conclude, these actions of students during exam preparation and outlined in the foregoing quotations are direct results of the need to pass the exam. Also, these actions of the student participants are akin to rational coping which is a problem-focused positive way of coping (Crego et al., 2016).

Interestingly, student 1310 stated in response to the research question: "concerned with what people say: If you do badly, they may think you are not smart.” The student's perceived social demand (real or imagined) contributes to greater examination-related anxiety (Deb et al., 2015; Wang \& Yeh, 2005). The solution of student 1310, however, is to apply herself to the task of studying, which includes going over the content "a lot, 
over and over and over again." These actions-during exam preparation-are a direct result of the need to pass the exam. Because teachers and teaching are inextricably linked to the examination preparation process and students' concerns, what are the implications of these findings for teachers and teaching?

\section{Implications for Teachers and Teaching}

Firstly, teaching by nature is complex. Teachers' daily tasks are varied. In addition to the delivery of lessons and an assortment of administrative and other duties, a key task is to address the learning and other needs of students. Chief among those other needs is that of students' well-being, which includes their

psychological/mental needs, which vary greatly from one individual to another (Shultz, 1990). If students are to self-actualize, that is to realize their full potential, their psychological/mental needs-among others-must be fulfilled. Teachers are critical to the success of this endeavor. This study highlights mental and emotional aspects of the examination preparation process, such as stress and examination-related anxiety that students experience, and which need to be addressed. In light of this, teachers are reminded that lesson content should have built-in considerations which address students' mental and emotional needs. Therefore, while teachers should not write these in their lesson plans, how they implement the lesson should reflect care and concern for students' experiencing these aspects of the examination preparation process. For example, teachers can provide information in a variety of ways, such as videos, paper-based information, having students quiz each other and develop mind map constructions, and give students examination-related tips and have them explain concepts being studied to each other. Van Manen (1995) suggested that the concept of teachers as pedagogues assumes that caring and being interested in the well-being of students motivates their practice. Additionally, during classes, teachers may provide opportunities for students to talk about aspects of the examinations which cause them concerns and provide them with coping strategies, which are rational, i.e., problem-focused positive ways of coping (Crego et al., 2016; Wang \& Yeh, 2005). This study provides examples of these coping strategies, for example, planning and carrying out personal research to "top-up" knowledge base.

In addition, the study reminds teachers to keep abreast of various revision strategies and to equip students to engage with these. It brings to the fore the use of flash cards and mind maps, but there are many sources of useful information which can also be found on the internet, and hence are very accessible. Akin to this is the need to continue to encourage social support, such as the use of study groups and family and friends, in the revision process as highlighted in this study. Jain (2013) wrote about revision tips useful for final or end-ofyear-examination preparation in higher education institutions and highlighted social support-a strategy also useful at the secondary level. Jain suggested exam students use family and friends in the revision process. They should ask family and other members of their social gathering to "quiz" them. The writer made the point that this social support is not only a good way to revise, but a good way to have a break from the hard work associated with revising for an examination.

Finally, the provision of extra classes by teachers to redress not completing the exam syllabus during the actual school term is not uncommon. It is an examination external factor which impacts the exam preparation process and causes concern for students in this study. For a multitude of reasons (too numerous for a thorough discussion in this short paper), extra classes promised students may not materialize. It is, however, the teachers' responsibility to ensure that promised extra classes come to fruition. If this is not done, students are left in the unenviable position of having to research and cover topics on their own, which may cause misunderstanding of subject content, thus leading to examination grades which may not be an appropriate reflection of the students' true capabilities. 


\section{Summary}

Factors that impacted exam preparation and caused concerns for London secondary school students were categorized as either examination external factors or the personal need factor, i.e., the need to pass the exam. Concerns caused by these factors were reduced and/or resolved by employing both school- and student-based solutions. What constitutes these factors and how they are resolved and/or reduced are displayed in Tables 1 and 2 in the appendix.

\section{Conclusion}

The findings of this study seem not to differ much from those in the literature. However, it offers a fresh look at the research issue. The findings draw on the thoughts of a group of students who are underrepresentedLondon secondary schools' students-and, to a certain extent, "voiceless" in the research literature regarding the examination preparation process.

Moreover, the study contributes to the literature by categorizing and defining factors impacting exam preparation for London secondary students as examination external factors and the personal need factor, that is the need to pass the exam, highlighting and discussing how these impact exam preparation and concerns they caused students, and how these concerns were reduced and/or resolved. The discussion of these factors in this study makes it a useful tool for teachers and those engaged in the tasks of organizing and preparing students for examinations. 


\section{References}

Ashworth, H. (2019). 10 high school study tips for students. The best way to get ready for your exams. https://www.liveabout.com/high-school-study-tips-for- students-how-to-pass-the-test-3196554

Bhopal. K. (2015). Race, identity and support in initial teacher training. British Journal of Educational Studies, 63(2), 197-211. https://doi.org/10.1080/00071005.2015.1005045

Bloemert, J., Paran, A., Jansen, E., \& van de Grift, W. (2019). Students' perspective on the benefits of EFL literature education. The Language Learning Journal, 47(3), 371-384, https://doi.org/10.1080/09571736.2017.1298149

Bourke., R., \& MacDonald, J. (2018) Creating a space for student voice in an educational evaluation. International Journal of Research \& Method in Education, 41:2, 156-168. https://doi.org/10.1080/09571736.2017.129814910.1080/1743727X.2016.1256983

Charteris, J., \& Smardon, D. (2019) The politics of student voice: Unravelling the multiple discourses articulated in schools. Cambridge Journal of Education, 49(1), 93-110. https://doi.org/10.1080/0305764X.2018.1444144

Crego. A., Carrillo-Diaz. M., Armfield, J. M., \& Romero, M. (2016). Stress and academic performance in dental students: The role of coping strategies and examination-related self-efficacy. Journal of Dental Education, 8o(2), 165-172.

Deb, S., Esben, S., \& Jiandong, S. (2015). Academic stress, parental pressure, anxiety and mental health among Indian high school students. International Journal of Psychology and Behavioral Sciences, 5(1): 26-34. https://doi.org/10.5923/j.ijpbs.20150501.04

Elliott, J. (1991). Action research for educational change. Open University Press.

GCSE Changes and Reforms. (2019). https://www.gov.uk/education/gcse-changes-and-reforms.

Independent Thinking. (2011). A brief history of the written exam. [Blog entry]. https://independentthinkingblog.wordpress.com/2011/o9/12/a-brief-history-of-the-written-exam/

Jain, S. (2013). Top 10 revision tips for your final (or first-year) exams. Independent. https://www.independent.co.uk/student/student-life/top-10-revision-tips-your-final-or-first-yearexams-8576161.html

Joffe, W. S. (2001). Investigating the acquisition of pedagogical knowledge: Interviews with a beginning teacher of the gifted. Roeper Review, 23(4), 219-226. https://doi.org/10.1080/02783190109554108

Kirkpatrick, R., \& Zhang, Y. (2011). The negative influences of exam-oriented education on Chinese high school students: Backwash from classroom to child. Language Testing in Asia, 1(3), 36-45. https://doi.org/10.1186/2229-0443-1-3-36

Locker, J., \& Cropley, M. (2004). Anxiety, depression and self-esteem in secondary school children: An investigation into the impact of standard assessment tests (SATs) and other important school examinations. School Psychology International, 25(3), 333-345. https://doi.org/10.1177/0143034304046905

Mayes, E. (2018). Student voice in an age of "security"? Critical Studies in Education. https://doi.org/10.1080/17508487.2018.1455721

Morgan, C. T., \& King, R. (1975). An introduction to psychology. McGraw-Hill.

Myyry, L., \& Joutsenvirta, T. (2015). Open-book, open-web online examinations: Developing examination practices to support university students' learning and self-efficacy. Active Learning in Higher Education, 16(2), 119-132. https://doi.org/10.1177/1469787415574053 
Powell, E. T., \& Renner, M. (2003). Analyzing qualitative data. University of Wisconsin-Extension USA. https://cdn.shopify.com/s/files/1/0145/8808/4272/files/G3658-12.pdf

Settlage, D. M., \& Wollscheid, J. M. (2019). An analysis of the effect of student prepared notecards on exam performance. College Teaching, 67(1), 15-22. https://doi.org/10.1080/87567555.2018.1514485

Shultz, D. (1990). Theories of personality. (4th ed.) Brooks/Cole Publishing.

Silverman, R. (2018). Exam preparation: Five key strategies. Simon Fraser University. https://www.lib.sfu.ca/about/branches-depts/slc/learning/exam-prep/exam-prep-5-strategies

The Mix. (2019). Revision tips. https://www.themix.org.uk/work-and-study/study-and-exam-tips/revisiontips-1238.html?

Van Manen, M. (1995). On the epistemology of reflective practice. Teachers and Teaching Theory and Practice, 1, 33-50.

Walls J., \& Holquist S. E. (2019). Through their eyes, in their words: Using photo-elicitation to amplify student voice in policy and school improvement research. In: Strunk K., \& Locke L. (Eds). Research methods for social justice and equity in education. Palgrave Macmillan. Cham, Germany.

Wang, H-F., \& Yeh, M. C. (2005). Stress, coping, and psychological health of vocational high school nursing students associated with a competitive entrance exam. Journal of Nursing Research 13(2)106-116.

Weale, S. (2018). Stress and serious anxiety: How the new GCSE is affecting mental health. The Guardian. https://www.theguardian.com/education/2018/may/17/stress-and-serious- anxiety-how-the-newgcse-is-affecting-mental-health 


\section{Appendix}

Table 1: Examination External Factors and Resolutions

\section{Examination External Factors causing} concerns for London upper secondary students.

Teachers not being able to cover all the topics in the syllabus during the regular school year.

The volume of information to be studied and work to be done.

Completing "timed papers" in the time allotted.

Changing examination questions each year.

No course work at AS and A levels to contribute to final grades, just a single examination.

GCSE changes and reforms in the UK
Resolution and/or Reduction: student and school based

School based: schools/teachers offering make-up sessions or extra classes.

Student based: independent study and researching to complete topics.

Student based: employ a "things-to-do list" and break down tasks into manageable sections.

School based: mock examinations.

Student based: study the notes taken during class and other information the teacher gives.

Student based: employ the ability to memorize information and stay calm.

School based: teachers learned the new requirements and how to implement these.

Student based: students learned the new requirements.

Student based: start revision the year before the actual examination is to be sat; attend study group and use different revision methods.

Students' being anxious because of the GCSE School based: relaxation sessions, yoga changes and reforms in the UK. classes and resilience programs. 
Minott, 2020

Table 2: Examination Factors Resulting From the Need to Pass the Exam and Resolutions

Examination Factors-which are a direct result of the personal need factor, that is the need to pass the exam-causing concerns for London upper secondary students

Memorizing information: "Not remembering what I studied," "Getting all that knowledge into my head," "Forgetting information" and "making sure I understand the specifications and key words in the questions"

Time management: "I was concerned about timing during the practice papers"

\section{Resolution and/or Reduction:}

student and school based
School-based: The school helped by giving frequent assessments, mock exams and papers.
Managing social demands: "I am concerned with what people say: If you do badly, they may think you are not smart."
Student-based: Independently completing lots of test papers-get the teacher to mark these and give feedback-quizzes and watch and listen to information related to exam topics, getting someone to ask the student questions about the topic being studied; careful to attend tutorials arranged by teachers, using mind maps and flash cards and seeking out a teacher or a knowledgeable friend for information and clarification.

Student-based: apply oneself to the task of studying, which includes going over the content multiple times.

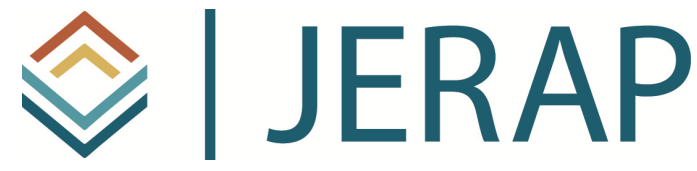
current relevant educational issues and processes. The aim is to provide readers with knowledge and with strategies to use that knowledge in educational or learning environments. JERAP focuses on education at all levels and in any setting, and includes peer-reviewed research reports, commentaries, book reviews, interviews of prominent individuals, and reports about educational practice. The journal is sponsored by the Richard W. Riley College of Education and Leadership at Walden University, and publication in JERAP is always free to authors and readers. 